\title{
Matrix. El género de la filosofía Alejandra Castillo Vega
}

\author{
Gabriela Méndez Cota
}

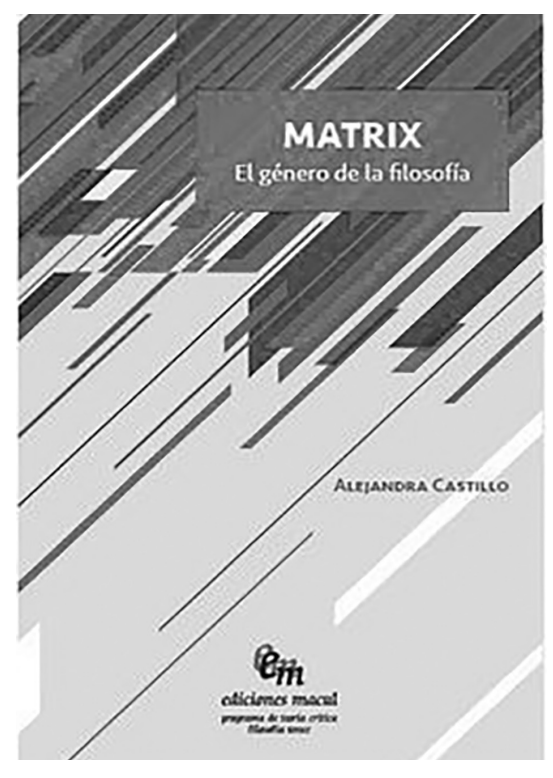

Alejandra Castillo Vega, Matrix. El género de la filosofía. Santiago de Chile: Ediciones Macul, 2019.
¿Por qué la madre? Nos podriamos preguntar. ¿Por qué el antes del antes, habría que llamarlo la cuestión de la madre? Más aún, ¿por qué habría que reservar un lugar, una definición de un cuerpo, que se describe univocamente como "la madre"? Volviendo a aquella pregunta con que se da inicio a El segundo sexo, de Simone de Beauvoir, cabría insistir: ¿acaso hay mujeres?, pero con una variación, ¿acaso hay madres? Alejandra Castillo, 2019

En Matrix. El género de la filosofía la chilena Alejandra Castillo desarrolla, a través de una introducción, doce ensayos breves y una entrevista, un modo feminista de leer y escribir filosofía, consistente en rastrear y poner de 
relieve los gestos retóricos con los cuales la disciplina instituye y perpetúa un dispositivo de género. El género se entiende aquí como un modo recurrente de hacer aparecer y desaparecer el cuerpo sexuado de la filosofía, a través de "un conjunto diverso de narraciones, técnicas y tecnologías que van constituyendo y describiendo lo masculino y lo femenino bajo las señas de la heteronormatividad reproductiva". ${ }^{1}$

Se trata de un dispositivo de poder que descansa en el supuesto célebremente descrito por Monique Wittig de que existe un "ya ahí" de los sexos, antecedente a cualquier pensamiento y a cualquier sociedad. Este supuesto instituye la metáfora del origen, de la matrix, ante la cual Castillo ofrece un modo de leer orientado a rastrear, atrapar, exhibir y desviar viejas dicotomías jerárquicas aún operativas en la filosofía contemporánea, tal y como se ha practicado en Chile, especialmente alrededor de la obra de Patricio Marchant. Ahora bien, lo interesante es que cuestionar el género de la filosofía, más allá de este contexto específico, se revela imprescindible no sólo para hacer de la diferencia sexual un objeto legítimo de investigación filosófica, también para lograr una mayor presencia institucional de las mujeres filósofas y la filosofía feminista.

La implicación radical de la propuesta de Castillo es el imperativo ético de atravesar los fantasmas universitarios del todo-saber, los mismos que alimentan la actual reducción del trabajo académico a una competencia descarnada al servicio del capital. Quizá a contrapelo de su propia experticia disciplinaria, lo que Matrix logra posicionar en primer plano es el medio material, dinámico, técnico e indeterminado de todo quehacer intelectual, que no es otro que la escritura.

Alejandra Castillo es profesora titular del Departamento de Filosofía de la Universidad Metropolitana de Ciencias de la Educación (UMCE) en Santiago de Chile. Es autora de más de una docena de libros de filosofía 
política, firmemente situada en la historia de los feminismos chilenos y latinoamericanos, así como de cuestiones estéticas en la teoría crítica contemporánea, entre los cuales cabe destacar: Adicta imagen (2020), Matrix. El género de la filosofía (2019), Crónicas feministas en tiempos neoliberales (2019) y Simone de Beauvoir. Filósofa, anti-filósofa (2017). Es además directora de la importante revista de cultura Papel Máquina y de la Colección Archivo Feminista de la editorial Palinodia. En una reciente entrevista en el suplemento cultural Klastos, Castillo describe indirectamente su escritura como una política de la alteración de los saberes instituidos: "El feminismo interrumpe la lógica androcéntrica de la universidad actual volviendo visible su cuerpo, sus exclusiones y violencias. Esta interrupción ha implicado la alteración de planes, programas, reglamentos y estatutos. En ese sentido, pienso la escritura feminista como un 'aparato' que crea contrainstituciona- lidad en la institucionalidad". ${ }^{2}$ Es hacia esta cuestión de la escritura feminista en los límites universitarios que quisiera orientar mi reseña de Matrix. El género de la filosofía.

Pese a la persistente minimización de su importancia para la filosofía, la diferencia sexual llega a operar ahí, afirma Castillo, como "principio oculto y ordenación nocturna de las marcas de los cuerpos", ${ }^{3}$ y ello se debe a que el relato filosófico desplaza metonímicamente esa diferencia hacia el concepto de lo femenino-materno erigido como totalidad. ${ }^{4} \mathrm{~A}$ partir de la contribución fundamental de Luce Irigaray, Castillo perfila la matrix como máquina de metaforización patriarcal que suplanta a la khôra, algo que, por lo demás, no tiene esencia, no es ni masculino ni femenino, sino (si acaso) pura temporalidad material. La matrix se convierte, no obstante, en la imagen del origen y la naturaleza, es decir, de un orden patriarcal que no sólo se constituye excluyendo a las

2 Sandra Hernández Reyes y Gabriela Méndez Cota, “Contra-escritura feminista: imagen, letra, tecnología. Entrevista con Alejandra Castillo”. Lado B: https://ladobe.com.mx/2020/09/contra-escritura-feminista-imagen-letra-tecnologia-entrevista-con-alejandra-castillo/

Castillo, Matrix, 17.

4 Castillo, Matrix, 19. 
mujeres de la filosofía, sino que empobrece y subordina la relación entre filosofía y existencia, entre escritura y vida. Tal subordinación se renueva cada vez que, en la historia y en el presente, aparecen nuevos nombres de lo femenino/materno - amor, familia, intimidad - para describir a las mujeres. Castillo rápidamente se desmarca del proyecto de elaborar un imaginario positivo de lo femenino-materno, en el cual ella detecta la lógica normalizadora del casi siempre. Si bien no resulta fácil deshacerse de una identidad culturalmente asigna$\mathrm{da}$, en este caso para renunciar a la descripción de la mujer como mujer entera, como madre casi siempre, Castillo insiste en preguntar: “¿Qué parte deja escapar este casi siempre? ¿Qué parte del reparto del mundo le corresponde a aquellas que se restan a la relación del dos y se nombran por fuera de la normalidad del casi siempre?". 5

Podemos entonces caracterizar la intervención filosófica de Castillo como una intervención queer, desviada respecto a las tentaciones hegemónicas, tan fuertes en Latinoamérica, de la ética de la diferencia sexual. Lo interesante es situar este tipo de intervención en un contexto latinoamericano específico. La filosofía chilena, demuestra Castillo, ante su propia imposibilidad, se aferra a una "vida" que no deja de figurarse en el cuerpo de mujer-madre. Pero no olvidemos, insiste Castillo hasta el final, que la mujer-madre no es otra cosa que la proyección del orden paterno. Éste sería el orden de la línea recta, de la funcionalidad y la eficiencia, de tal forma que su interrupción consistiría en inclinar la línea y torcerla hasta des-rentabilizar la obediencia al mandato paterno del amor, la reproducción y "ese progreso llamado futuro". ${ }^{6}$ Ahora bien, ¿implica esto un rechazo absoluto, por lo demás familiar, de lo materno y la maternidad en general? Más bien, sugiere la autora, tal vez sea en la rareza, en la duda "que implica la 
denegación continua con el nombre, donde sea posible sugerir el gesto del antes del antes, gesto del aferrarse".

El antes del antes no se declara pasivo y uniforme, sino como huella que pone en marcha algo que no se sabe. No se figura como un cuerpo dado sino como un cuerpo técnico, en el entendido de que "...no hay cuerpo sin técnica. Es en la confusión entre cuerpo y técnica (escritura, imagen, aparato) donde se despliega el dispositivo corporal". ${ }^{8}$ En clave de tecnicidad originaria, la escritura permitiría refigurar a la mujer-madre como algo más y algo menos que una proyección del orden patriarcal, quizá como punto de fracaso del dispositivo de género en su totalidad. Esto me sugiere la propia Matrix cuando Castillo refiere al psicoanálisis de las parafilias en tanto evocación de "un movimiento de olas, un ir y venir de marea", e incluso como "un retorno, una vuelta atrás" a un lugar — una "madre marina" - donde tienen cabida otros cuerpos y otras sexualidades.
Matrix concluye con el testimonio de "una conversación marina acunada en el vaivén de una amistad que se recoge y expande según el movimiento de las mareas del mar". Ahí, Castillo responde a una pregunta del filósofo chileno Willy Thayer con otra interrogante: “¿Cuál es el tiempo del feminismo? Esto no es distinto a preguntar, ¿cuál es el cuerpo del feminismo?". ${ }^{10}$ Sería en extremo desafortunado inscribir el feminismo en un tiempo lineal, es decir, en un cuerpo erecto, por más que ello resulte funcional para la política o eficiente para la universidad. Suponer, en cambio, que el feminismo se inserta en la temporalidad deconstructiva -incalculable - del texto, permite comprenderlo como una operación que no es ni general ni particular sino múltiple y singular. Lo que hace tan "monstruoso" al feminismo no sería otra cosa que, como la tejedora Aracné, "no ve límites de nacimiento, ni de clases, ni tampoco compromiso alguno de género". ${ }^{11}$ 
$\mathrm{Al}$ respecto me interesa enfatizar el vínculo estrecho entre esta monstruosidad textual y la noción de una tecnicidad originaria, subversiva precisamente en virtud de su materialidad. ¿Cómo volver a esta materialidad y desde ahí torcer, desviar la línea recta de la disciplina, del todo-saber universitario cuya matrix se presenta hoy como la subsunción capitalista de todo tipo de activismos académicos y militancias algorítmicas?, ¿cómo salir de ahí?, preguntaba Sarah Kofman. La solución Castillo no la encuentra en la filosofía sino en otras escrituras que apuntan no a la naturaleza sino al "artificio en el antes, la letra como origen". ${ }^{12}$ Así, se sustraería de la matrix una escritura poética como la de Gabriela Mistral, "que con tenacidad desdibuja la figura de la mujer descrita con la intensidad de las señas de la materialidad y la maternidad", ${ }^{13} \mathrm{y}$ una escritura anti-filosófica como la de Simone de Beauvoir. Escribir de otra manera es alterar este dispositivo, interrumpirlo, indeterminarlo, así sea dentro de ciertos límites.

En 1977, la revista británica Radical Philosophy publicó un ensayo de la filósofa francesa Michèle le Doeuff, autora de El imaginario filosófico (1989) - libro que bien valdría releer hoy junto a Matrix. El género de la filosofia-. Le Doeuff vaticinaba en 1977 que:

...el futuro de la lucha de las mujeres por el acceso a lo filosófico se jugará en el terreno del trabajo plural. Más aún porque los grupos de trabajo probablemente adquirirán un poder estructurante [...] análogo o equivalente al de la institución: son ellos los que permiten evitar la posición [comentarista, subordinada] de Eloísa [...] y su opuesto, que es una inversión excesiva del deseo de filosofar en "lo académico" o "lo institucional". ${ }^{14}$

\section{Castillo, Matrix, 121}

Castillo, Matrix, 47.

14 Michèle le Doeuff, "Women and Philosophy", Radical Philosophy 17 (1977) https://www.radicalphilosophy.com/article/women-and-philosophy 
En este sentido, resulta interesante poner en relación la intervención de Castillo con la creciente organización e institucionalización de la filosofía hecha por mujeres en el mundo de habla hispana, cada vez más pero no siempre como filosofía feminista. Por un lado, Las filósofas tienen la palabra, libro de entrevistas realizadas a lo largo de varios años por la investigadora mexicana Fanny del Río, ${ }^{15}$ deja claro que en México, hasta el momento, ser una mujer filósofa no ha sido equivalente a intervenir, de modo feminista, en el quehacer filosófico. El panorama presentado por Del Río, a través de una pluralidad de perspectivas de filósofas consolidadas en el ámbito académico, nos deja con el pendiente de convocar nuevas y múltiples intervenciones feministas en el relato de la filosofía en México, es decir, en su devenir disciplinario o institucional. Para ello, sin duda será en extremo útil tomar en cuenta ejercicios situados como el que emprende Alejandra Castillo para la filosofía en Chile y que incluye, de modo estratégico, una consideración filosófica de las escrituras subversivas de las poetas, políticas e intelectuales chilenas que, de otro modo, no serían de interés para el saber disciplinario.

Por otro lado, Fuera de sí mismas. Motivos para dislocarse, antología editada por Ana Carrasco Conde y Luciana Cadahia, ${ }^{16}$ proviene de un proyecto de investigación trasnacional en donde once filósofas hispanoparlantes suman voces para dislocar la problemática del género y redirigir su tematización hacia la cuestión de hacer filosofía de otro modo. Si bien este trabajo evidencia de un modo claro la madurez y sofisticación de la filosofía feminista de nueva generación y de corte académico, en algunos circuitos del mundo de habla hispana, también nos lleva a retomar la aportación singular de Matrix a partir de la cuestión de la relación entre filosofía, feminismo y universidad.

15 Fanny del Río, Las filósofas tienen la palabra (Ciudad de México: Siglo XXI, 2019), 126.

16 Luciana Carrasco Conde y Luciana Cadahia, eds., Fuera de si mismas. Motivos para dislocarse (Barcelona: Herder, 2020), 399. 
$\mathrm{Al}$ articular la cuestión del feminismo con la pregunta por la universidad -ambas interrogantes por la operación de la letra, es decir, "que instituye, forma y mueve, pero también destituye, deforma y detiene"- ${ }^{17}$ Castillo nos invita a aspirar a algo más que una "filosofía feminista", una pedagogía de la lectura o un método para identificar cuerpos dominantes y cuerpos excluidos. Si bien puede parecer indispensable legitimar disciplinariamente la filosofía feminista, la tarea de fondo es crear alternativas a la constitución heteronormada del saber. ¿Podría lograrse eso sin una experimentación multiplicadora, con los formatos y las infraestructuras simbólico-materiales de la escritura y publicación académicas? De un modo aún más subrepticio que el relato filosófico, son esas infraestructuras las que perpetúan el orden de la línea recta, la eficiencia y la funcionalidad de la aut(e)oría, la propiedad intelectual como competencia intelectual, los derechos de lucro individual o reproducción, en suma, el cuerpo sexuado de la universidad.

17 Castillo, Matrix, 79. 